\title{
Control System for Less than Wind Turbines 1500W
}

\author{
D. Icaza*, A. Pauta, G. Saguay and F. Solis \\ Catholic University of Cuenca, Cuenca, Ecuador
}

\begin{abstract}
Using wind power generation is another alternative for remote homes, where there is no electricity grid. Especially in Ecuador there are several places where the wind resource is really stable for the year, though at times the wind regime it becomes turbulent wind speeds become quite high exceeding $12 \mathrm{~m} / \mathrm{s}$ affecting the wind turbine components.

Generally in the Ecuadorian highlands are available permanent winds of medium intensity capable of generating electricity, but by having a system of turbulence for short periods of time it jeopardizes the deployed equipment and therefore the investments made by what this study guarantees the stability of small wind turbines that are very useful in our environment to generate electricity in field type housing shelters.
\end{abstract}

Keywords: Control, Wind Generators, Protection.

\section{INTRODUCTION}

The integrity and security in the delivery of electricity from the source to the load depends largely on electrical protection system against failures and external or internal disturbances, these failures are diverse and can be overload by overcurrent or short circuit, low frequency among others.

The main function of a control system forewarn the electrical service and equipment before the failure occurs.

The components of a wind turbine are designed to last about 20 years. This means they will have to endure more than 120,000 operating hours, often under stormy weather conditions.

In our case we endeavor to design the control system, with tests corresponding operating and thus make available to society a mechanism capable enough to prevent deterioration of the components of wind generators in the middle of Ecuador and therefore the energy service is not affected due to the lack of control mechanisms on small wind turbines that are manufactured here and even lack of standards, given the experience that many of these machines being developed in our country do not care of this factor has trigger such as engine overspeed and component failure due to their high speed for short periods of time.

The energy conversion equations describing the total power generated by the wind generator designed presented. In order to validate this simulation model,

*Address correspondence to this author at the Catholic University of Cuenca, Cuenca, Ecuador; Tel: 0985154839; Fax: 07 4035232;

E-mail: dicazaa@ucacue.edu.ec the energy conversion equations were coded with MATLAB V13.2, is used for optimization of resources to be a design tool. A block diagram approach was used during the simulation with MATLAB. In order to validate and tune output results expected at the site was used to validate the simulation program data under various conditions.

\section{OBJECTIVES}

- To avoid equipment damage due to the significant increase in lower wind speed $1500 \mathrm{~W}$ generators that are installed in Ecuador.

- Maintain a high level of Quality of Service (stability and continuity), avoiding where possible outages.

- Design a control system capable of preventing destruction or deterioration of the internal elements of the shaft speeds of the electric generator of a wind turbine.

\section{Mathematical Modeling}

Then the block diagram of the speed control system is presented [1].

In the Figures $\mathbf{1}$ and 2, a speed control system for isolated power system is shown. The air brake controls the input speed wind turbine in order to take into account changes in load. $\Delta \mathrm{L}(\mathrm{s})$ within the power distribution network. Effective rotational inertia, $\mathrm{J}$, is equal to 4000 and the constant friction is very close to zero. The factor regulating the rate at steady state, $R$, is very small, less than 0.1 . The stabilization time is $10 \%$. 
Torque load

$\Delta \mathrm{L}(\mathrm{s})$

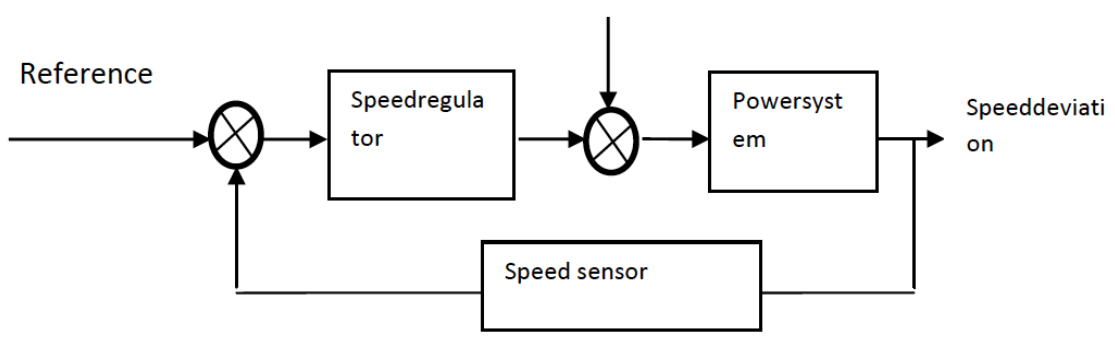

Figure 1: Block diagram of the automatic control system.

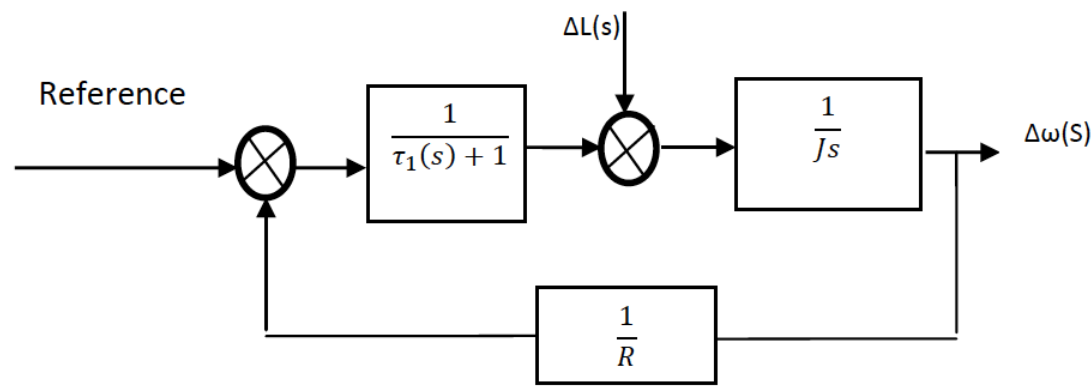

Figure 2: Block diagram in the Laplace domain [3].

We obtain the transfer function:

$H(s)=\frac{\frac{1}{(0.1 s+1)} \cdot \frac{1}{4000 s}}{1+\frac{1}{(0.1 s+1)} \cdot \frac{1}{4000 s}}$

$H(s)=\frac{1}{400 s^{2}+4000 s+1}$
To determine whether the behavior of the system is stable, unstable or marginally stable according to the mathematical model used to simulate proceeded in Matlab identifying the locus of the roots using the command rlocus was established that the system is stable as a center especially it is far from the real axis. See Figure 3.

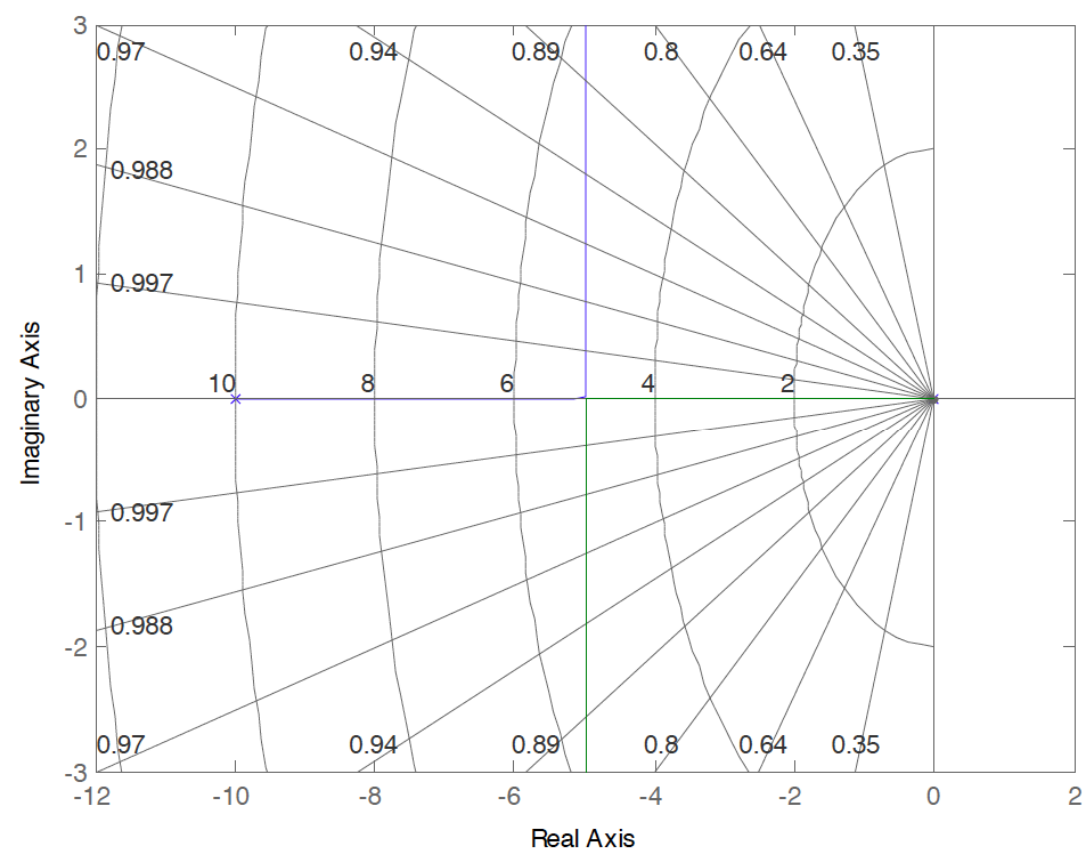

Figure 3: locus of the roots. 


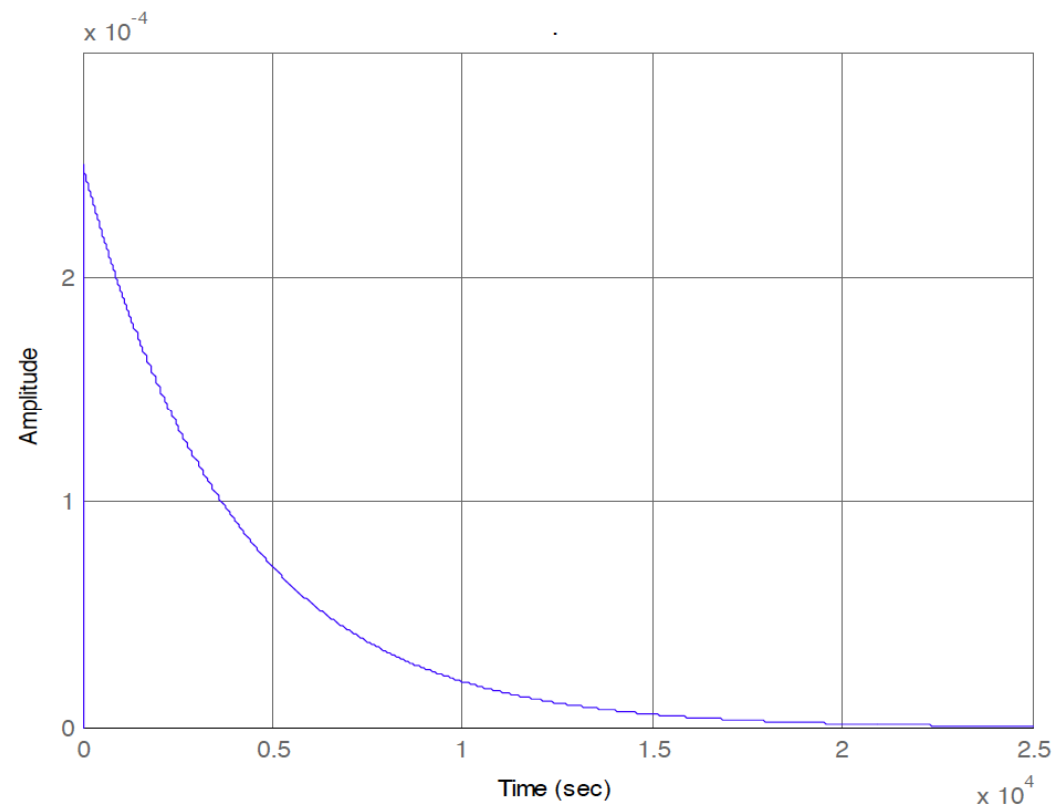

Figure 4: Impulse response.

It has also been simulated impulse response to the system and has obtained the graph No. 4 which shows the graph that gradually declines over time.

\section{Design Phase}

The control system must be different depending on the size of the turbine. For small machines, the control is simple and usually passive, on the contrary, for large machines - medium and high power - the control system will be more complicated because of the many parameters to be measured and increased accuracy required, but will represent a cost, although high, is small compared to the total system cost [2].

Thus, in our particular case passive controls make your measurements in the simplest possible way and use natural forces to act, while the active control systems using electrical and mechanical systems to achieve its purpose.

The main objectives of a control system are:

- Get automatic operation of the turbine.

- Getting the turbine to operate in line with the wind (direction, power control, etc.).

- Decide on / off the generator and successfully perform the starts and stops the turbine.

- Protect the system (overspeed, vibration, overheating, curls interconnect cables).

- $\quad$ To maximize system performance.
- To increase the life of the wind turbine (minimizing unintended burdens that may arise).

For the design of the wind turbine we have been divided into nine parts, the same as a specific role.

1. Aspas

2. Brake

3. Electromagnet

- $\quad$ swivel

4. Base engine

5. Aspa guide

6. Tube and support base

7. lead acid battery

8. Speed sensor or anemometer

9. Electromechanical relay

The control system must necessarily include testing or diagnosis operation immediately detect a malfunction and should immediately stop the speed of the turbine, thereby ensuring system costs and service reliability.

The control system consists of three stages:

1. Input stage: This stage is responsible for driving signals from the speed sensor arranged on the axis of the central electrical generator to be processed immediately when too high a speed is 
detected and send orders to the electromechanical actuator type shoe I acted on said axis.



Figure 5: General diagram generation and control system.

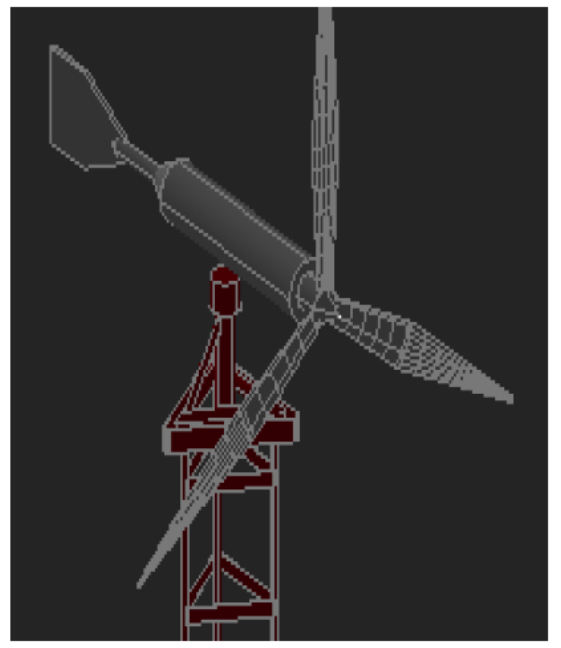

Figure 6: Wind turbine design built for testing.

2. Warning Signs: This stage is responsible for collecting the signals corresponding to anomalous situations in vital systems, commanding absolute priority over any other order the emergency stop of the wind, until it disappears the cause that caused the emergency.

3. Output stage: This stage transmits electrical signals from execution of instructions received from the control system operating the corresponding actuator (air brake). When it is detected that the speed is normal aerodynamic braking system returns to its initial state and therefore regular electricity generation.

\section{Representative Photo of Electromechanical Control System}

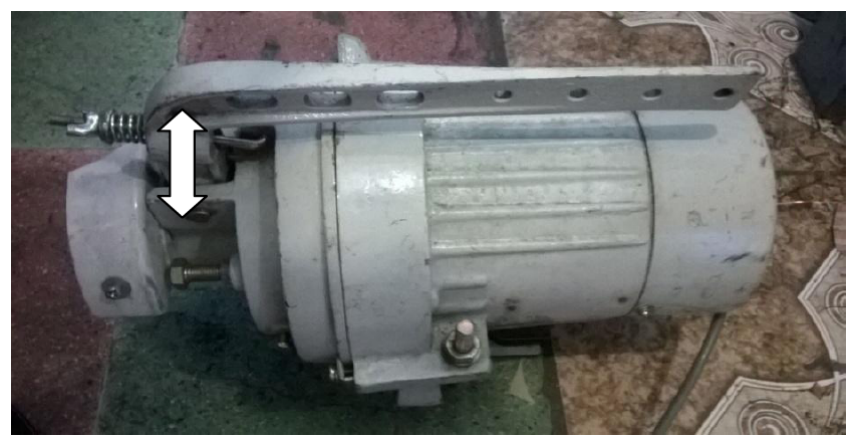

Figure 7: Electromechanical actuator mounted on the electric generator.

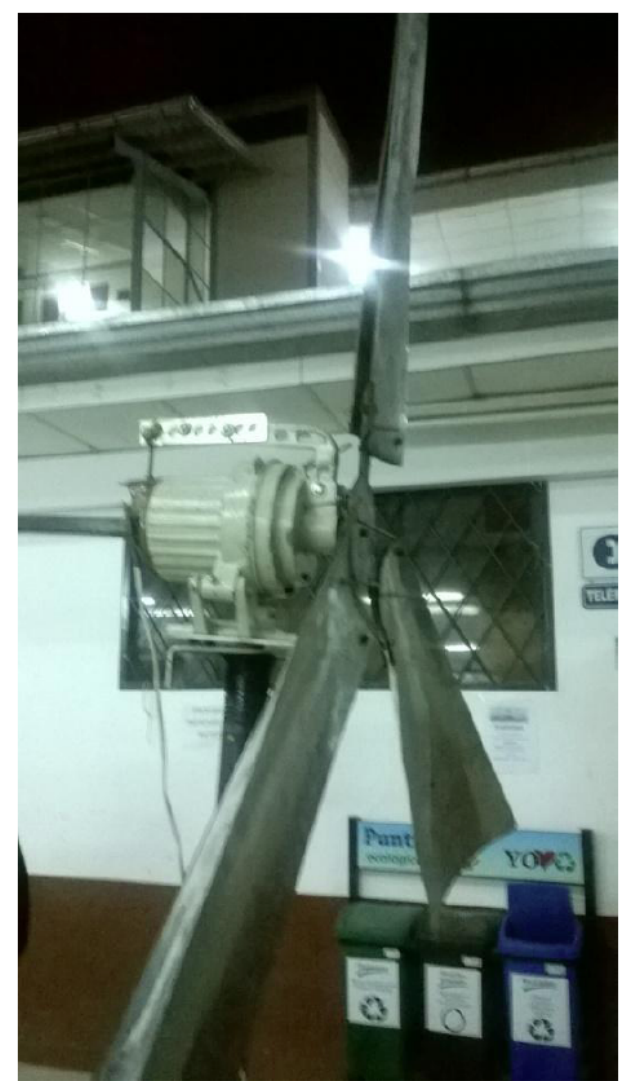

Figure 8: Overview of the wind generator control system mounted speed.

Once designed the control system and made the corresponding assembly, necessary to examine the whole system of wind power generation, describing the main formulas and simulating in MATLAB V13.2 program to verify the behavior of the theoretical curves compared measured results. 


\section{Wind Power System} [3];

The power of a particular wind turbine is given by

$P_{W T}=0.5 * C_{p} * \rho_{\text {air }} * v^{3} * \eta_{\text {aer }}$

Where; $P_{W T}=$ Wind power sweep produced by the blades per unit area. $C_{p}=$ Betz power coefficient. $\rho_{\text {air }}=$ Air density and $v$ is the wind velocity.

Taking into account the internal performance of the wind turbine, the following can be written;

$\eta_{\text {aer }}=\eta_{\text {fmec }} \cdot \eta_{g} \cdot \eta_{m p}$

Where; $\eta_{\text {fnec }}, \eta_{g}$ are mechanical friction and generator efficiencies respectively and the efficiency speed multiplication box is $\eta_{m p}$.

The power output of the wind turbine in equation (1) can be expressed in three-phase power AC as;

$P_{3 f}=\sqrt{3} \cdot \eta_{c 1} \cdot U_{\text {line }} \cdot I_{\text {line }} \cdot \operatorname{Cos} \varphi$

With three phase AC power is $P_{3 f}$, line current $I_{\text {line }}$, represents power factor $\operatorname{Cos} \varphi$, and the electric conversion efficiency is referred to as $\eta_{c 1}$.

\section{Controller}

Generally, the controller power output is given by;

$P_{\text {Cont }-d c}=V_{b a t}\left(I_{\text {rect }}\right)$

Where; $V_{\text {bat }}$ is multiplication of the nominal voltage DC in the battery for any particular system and $I_{\text {rect }}$ represent the output current of the rectifier in DC.

\section{Battery Performance Model}

Normally, batteries in a hybrid system are connected in series to obtain the appropriate nominal bus voltage [9]. Therefore, the number of batteries connected in series in a battery banks is calculated as follows;

$N_{S B a t}=\frac{V_{P V}}{V_{B a t}}$

\section{Inverter, Charger, and Loads Performance Model}

The characteristics of the inverter are given by the ratio of the input power to the inverter $P_{i n v-i p}$ and inverter output power $P_{i n v-o p}$. The inverter will incur conversion losses and to account for the inverter efficiency losses, $\eta_{i n v}$ is used [4];

$P_{i n v-i p} \cdot \eta_{i n v}=P_{i n v-o p}$

In many applications, load may not be served with the desired amount of energy. This situation is described as loss of load probability (LLP) and can be calculated using the following equation and also, LLP can represent the system reliability [7];

$L L P=\frac{\text { Energy_Demand }}{\text { Energy_Served }}$

The AC power of the inverter output $P(t)$ is calculated using the inverter efficiency $\eta_{i n v}$, output voltage between phases, neutral $V_{f n}$, for single-phase current $I_{o}$ and $\operatorname{Cos} \varphi$ as follows [8];

$P(t)=3 \eta_{i n v} V_{f n} I_{o} \cos \varphi$

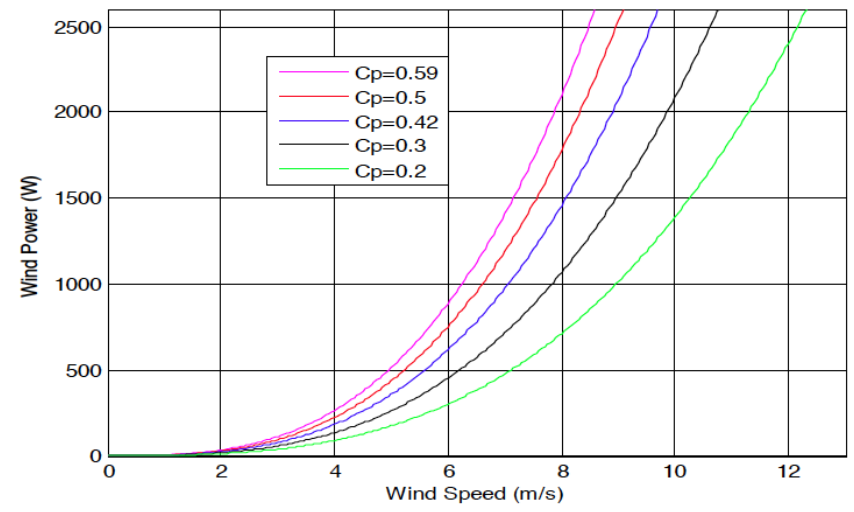

Figure 9: Power-speed curve for different values of Betz Coefficient [10].

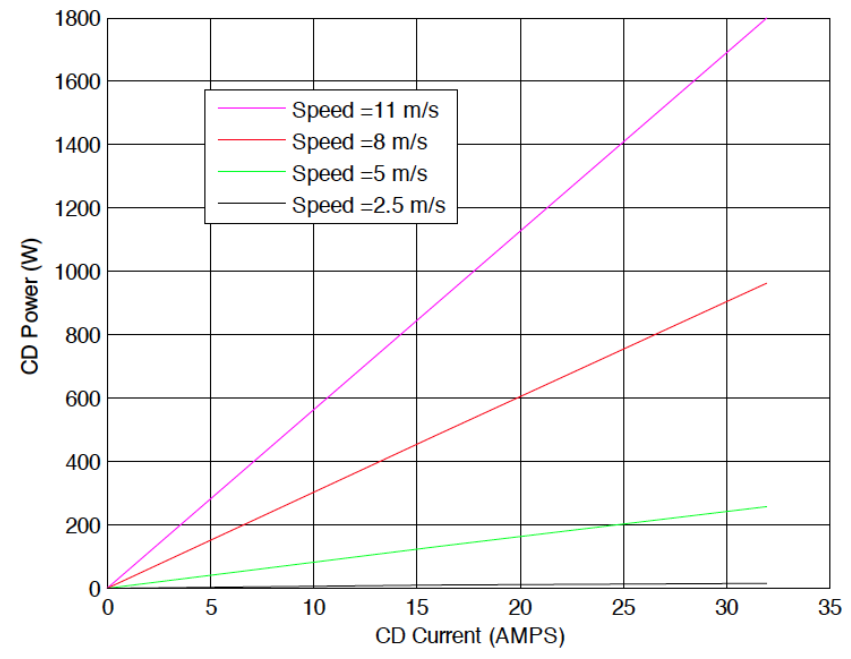

Figure 10: DC Power- DC Current for wind Speed $(\mathrm{m} / \mathrm{s})$. 


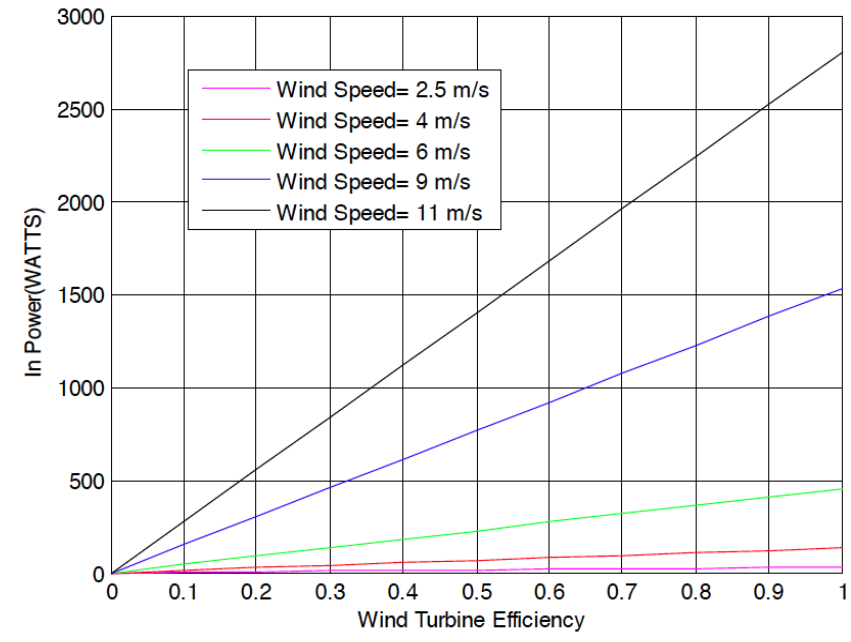

Figure 11: Energy conversion efficiency at various wind speeds [11].

\section{Model Validation}

In order to validate our numerical prediction model described, we have built a wind generator and implement mechanisms that allow for performance testing. After giving different velocities to the prototype it verified that from $14 \mathrm{~m} / \mathrm{s}$ the electromechanical actuator actually goes into action and thereby slowing the shaft of the electric generator, after about 4 seconds of time the speed is sensed again and down the electromechanical actuator separating from the shaft of the electric generator, so it is possible to determine that the model employed in good agreement with the director field trials.

It is quite clear from these figures that our numerical model predicted quite the drive control system.

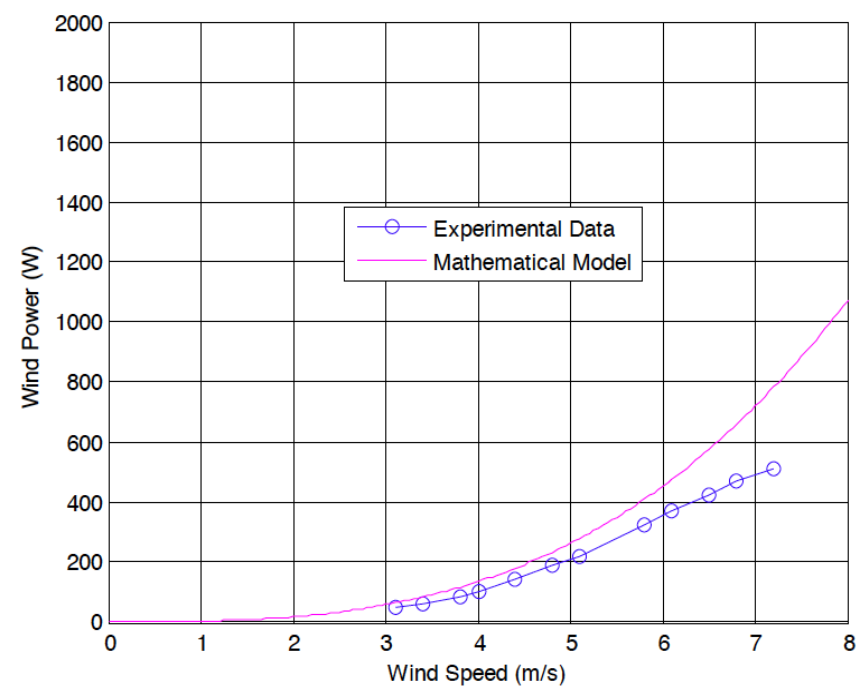

Figure 11: Comparison between Wind Turbine data (Ikhsan et al. [7]) and model's prediction.

\section{CONCLUSIONS}

For the purpose of validating the simulation model mentioned above were coded with MATLAB V13.2 and used as an optimization and design tool. A block diagram approach was used for the simulation with MATLAB. In order to validate and tune the predicted results, the in situ data were used under various conditions. The prediction model fair comparison with the data. We certainly believe that this model can be used as a tool for design and optimization with great confidence.

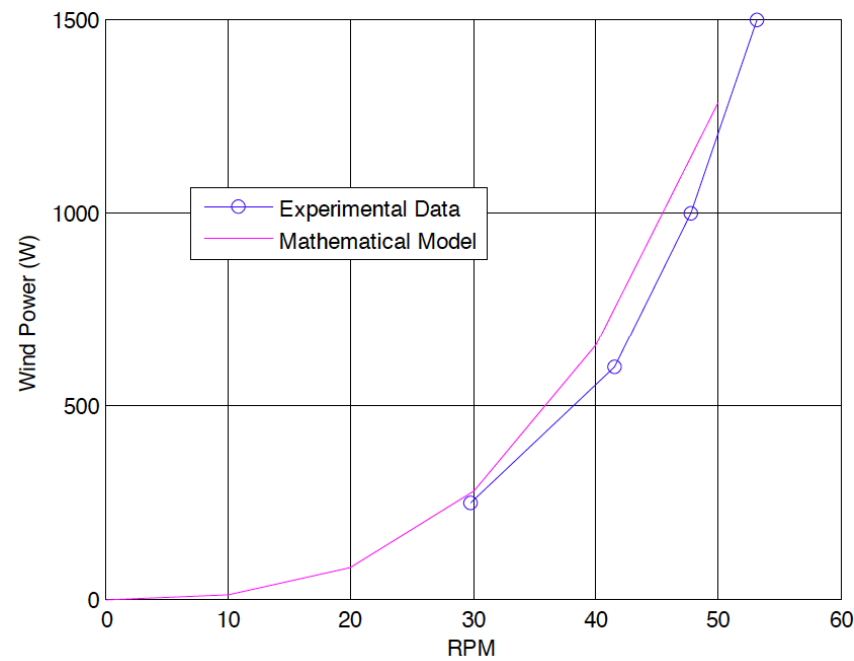

Figure 12: Comparison between Wind Turbine data (Yueqing Zonhan Wind Power Co. Ltd [5] and Bosma B. and Kallio [6]) and model prediction.

In addition, we make a comparison between the theoretical curves and concerning the most significant parameters such as wind generator power and speed experimental data.

\section{NOMENCLATURE}

$\mathrm{b}=$ Coefficient of friction of the generator referred at wind turbine $[\mathrm{N}-\mathrm{m} / \mathrm{rad} / \mathrm{s}]$

$\mathrm{R}=$ Regulation factor

$\tau_{1} \quad=$ Time of stabilization

$\operatorname{Cos} \varphi=$ Power factor referred to wind turbine

$C_{p} \quad=$ Betz power coefficient

$I_{0} \quad=$ Single-phase current

$l_{\text {line }}=$ Line current referred to wind turbine

$I_{\text {rect }}=$ DC current to the rectifier output 


\begin{tabular}{|c|c|c|c|}
\hline $\mathrm{J}$ & $=$ Inertia moment of the generator $\left[\mathrm{Kg}-\mathrm{m}^{2}\right]$ & Cont & $=$ Controller \\
\hline K & $=$ Coefficient proportional to input kinetic & $c 1$ & $=$ Electric conversion referred to wind turbine. \\
\hline & & $f n$ & $=$ Phase neutral \\
\hline $\mathrm{Kp}$ & $=$ Coefficient of the controller & fmec & $=$ Mechanical friction \\
\hline LLP & $=$ Loss of load probability & inv-ip & $=$ Inverter input \\
\hline $\mathrm{L}_{\mathrm{a}}$ & $=$ Inductance of armature $[\mathrm{H}]$ & inv-op & $=$ Inverter output \\
\hline$N_{S B a t}$ & $=$ Number of batteries connected in series & $p$ & $=$ Power \\
\hline$P(t)$ & $=A C$ power of the inverter output & $\mathrm{pc}$ & $=$ Power conditioning \\
\hline$P_{3 f}$ & $=$ Three phase $\mathrm{AC}$ power of the wind turbine & rect & $=$ Rectifier \\
\hline$P_{W T}$ & $=$ Wind power sweep produced by the blades & SBat & $=$ Batteries connected in series. \\
\hline$P_{\text {Cont-dc }}=$ & $=$ Power Controller & total & $=$ Total \\
\hline$P_{\text {inv-ip }}=$ & $=$ Inverter input power & $W T$ & $=$ Wind Turbine \\
\hline$P_{\text {inv-op }}$ & $=$ Inverter output power & $3 f$ & $=$ Three phase $\mathrm{AC}$ \\
\hline
\end{tabular}

$\mathrm{R}_{\mathrm{a}} \quad=$ Resistance of armature $[\Omega]$

RPM = Revolutions per minutes

$U_{\text {line }}=$ Line voltage referred to wind turbine

$v \quad=$ Wind velocity

$V_{\text {bat }}=$ Nominal voltage DC in the battery

$V_{f n} \quad=$ Phase- neutral voltage

\section{Greek Alphabet}

$\eta_{\text {aer }} \quad=$ Wind turbine efficiency

$\eta_{\text {fmec }}=$ Mechanical friction efficiency

$\eta_{g} \quad=$ Generator machine efficiency

$\eta_{c 1}=$ Electric conversion efficiency is referred to wind turbine

$\eta_{\text {inv }} \quad=$ Inverter efficiency

$\rho_{\text {air }} \quad=$ Air density

\section{Subscripts}

$$
\begin{aligned}
& \text { aer } \quad=\text { Aero generator } \\
& \text { Air } \quad=\text { Air } \\
& \text { bat } \quad=\text { Battery }
\end{aligned}
$$

\section{ACKNOWLEDGEMENT}

The research work presented in this paper was made possible through the support of the Catholic University of Cuenca.

\section{REFERENCES}

[1] Sami S, Icaza D. Numerical Modeling, Simulation and Validation of Hybrid Solar Photovoltaic, Wind turbine and Fuel Cell Power System. J Technol Innovat Renew Ener 2015 ; 4(3) 80-90. http://dx.doi.org/10.6000/1929-6002.2015.04.03.1

[2] Binayak B, Shiva RP, Kyung-Tae L, Sung-Hoon A Mathematical Modeling of Hybrid Renewable Energy System: A Review on Small Hydro-Solar-Wind Power Generation. Int J Precision Eng Manufacturing-Green Technol 2014; 1(2): 157-173.

http://dx.doi.org/10.1007/s40684-014-0021-4

[3] Sami S, Icaza D. Modeling, Simulation of Hybrid Solar Photovoltaic, Wind turbine and Hydraulic Power System. Int J Eng Sci Technol 2015; 7(9).

[4] Engin M. Sizing and Simulation of PV-Wind Hybrid Power System. Int J Photoener 2013; 2013: 1-10. ID 217526.

[5] Bosma B, Kallio G. Renewable-energy labs for an undergraduate energy-systems course. Am Soc Eng Educ 2009.

[6] Zonhan Y. Wind Power Co. Ltd., Operating \& Installation Manual. ZH1.5kw wind turbine system 2015.

[7] Ikhsan M, Purwadi A, Hariyanto N, Heryana N, Haroen Y. Study of Renewable Energy Sources Capacity and Loading Using Data Logger for Sizing of Solar-Wind Hybrid Power System" 4th International Conference on Electrical Engineering and Informatics (ICEEI 2013). http://dx.doi.org/10.1016/j.protcy.2013.12.293

[8] Singh G, Chauhan DS. Development and Simulation of Mathematical Modeling of Hydraulic Turbine. ACEEE Int $\mathrm{J}$ Cont Instrument 2011; 2(2): 
[9] Saib S, Gherbi A. Modeling and Simulation of Hybrid Systems (PV/Wind/Battery) connected to the Grid, International Conference on Electrical Engineering and Automatic Control, Setif, 24-26 November, 2013.

[10] Department of Energy. Potential Benefits of Distributed Generation and Rate Related Issues that may Impede their
Expansion, A Study Pursuant to Section 1817 of the Energy Policy Act of 2005, 2007.

[11] Sirasani K, Kamdi SY. Solar Hydro Hybrid Energy System Simulation. Int J Soft Comp Eng 2013; 2(6): 500-503.

DOI: http://dx.doi.org/10.6000/1929-6002.2016.05.03.3

(C) 2016 Icaza et al.; Licensee Lifescience Global.

This is an open access article licensed under the terms of the Creative Commons Attribution Non-Commercial License (http://creativecommons.org/licenses/by-nc/3.0/) which permits unrestricted, non-commercial use, distribution and reproduction in any medium, provided the work is properly cited. 